\title{
The time-series relation between monthly sales and
}

\section{stock prices}

\author{
Chien, Hsueh-Fang ${ }^{1}$ Lee, Shu-Hua ${ }^{2}$ Tsai, Yann-ching ${ }^{3}$ \\ ${ }^{1}$ National Dong Hwa University, Taiwan \\ ${ }^{2}$ National Taipei University, Taiwan \\ $*^{3}$ National Taiwan University, Taiwan \\ *Contact Author: Yann-ching Tsai, email: yanntsai@ntu.edu.tw
}

\begin{abstract}
Focuses on several key industries like Textile, Plastics, and Electronics, this study applies the Vector Autoregressive Moving Average (VARMA) Model on the industrial sales index and industrial stock prices index to observe the dynamic relationship between sales and stock prices. Our empirical result has shown a consistent pattern of relationship between sales and stock prices among all industries in the sample. The fitted industrial VARMA model indicated a one-way causal relationship from sales to stock prices. The sales figure could transmit relevant information to the market and influence the stock prices. On the other hand, stock prices do not carry relevant information about future sales. Therefore, the results of this study support the hypothesis of information content of the monthly sales announcements.
\end{abstract}

Keywords: time series model, leading indicator, sales, stock price

\section{Introduction}

In Taiwan, most studies using long window period document the significant positive relationship between stock price changes and unexpected earnings. However, only few studies looked at the stock market reaction to the annual/quarterly earning announcements. The result of most of these event studies has failed to support the hypothesis of information content of the annual/quarter earnings announcements. This lack of information content result may be related to the disclosure rule by the securities exchange act that all Taiwanese public Companies are required to file and announce their monthly sales figure by the $10^{\text {th }}$ day of the following month (Taiwanese Security Exchange Act Article $363^{\text {rd }}$ clause). This monthly sales announcement requirement provided additional source of information to investors on a more timely basis than annual/quarterly reports. If we assume there is a linkage between monthly sales and annual/quarterly earnings, the monthly sales announcement would transmit earnings related information to the market.

Consequently, there would be little incremental information to be released at the annual/quarterly earnings announcement since costs of good sold and expenses are more predictable compared to sales revenue. As we mentioned earlier, in the market evaluation model, stock prices are related to the expected future earnings. If we expect current earnings will serve as important source of information for investors' prediction of future earnings, then current earnings would influence stock prices and show earnings as leading indicators of prices. This is the main stream viewpoint held by most researchers. However, if investors use other future earnings related information not conveyed by current earnings (e.g., plant expansion) in their prediction of future earnings, we would expect stock prices to be the leading indicator of future earnings. For example, Beaver, Lambert \& Morse [4] discovered that the earnings prediction model based on stock prices is superior to the time series earnings prediction models. And, Beaver, Lambert \& Ryan [7] used market return as independent variable and earning changes as the dependent variable in a reverse regression model and found prior stock prices changes would impact the changes of current earnings.

Beaver, McAnally, \& Stinson [8] considered the interaction between stock prices and earnings in the same time period 
and proposed the use of simultaneous equations as the way of improving the problem of parameter estimation bias associated with single equation model. In a more recent study, Allen, Cruickshank and Morkel-Kingsbury [9] apply the vector auto-regressive model and conclude that earnings variable is not a leading indicator of stock prices. Lee, Myers, and Swaminathan [10] use a similar model to show accounting earnings could have predictive power to stock prices.

In summary, prior research did not provide conclusive answer to whether earnings are the leading indicator of stock prices or vise versa. This study will investigate this importance issue further by examining the dynamic relationship between stock prices and monthly sales. Even in countries where disclosure of sales number on a monthly basis is not mandatory, information regarding company sales is often available to analysts prior to the release of accounting earnings. Therefore, our findings could potentially contribute to the "lead-lag issue" between accounting information and stock prices by focusing on a more timely accounting numbers- sales.

There are five sections in this article. The first is an introduction. The second section presents the research hypothesis and methodology. The third section identified variables in the model and sample selection. The fourth section is the empirical analysis. Conclusion is provided in the fifth section.

\section{Research Hypothesis and Methodology}

Many accounting/finance literature used stock evaluation model which denoted the stock price of company $i$ at time $t$ as:

$$
P_{i t}=\sum_{l=1}^{\infty} \beta_{i}^{l} E_{t}\left(X_{i t+l}\right)
$$

Where $\beta_{i}$ is the discount factor, $X_{i t}$ is $i$ company's earning at time $t$.

Equation (1) indicated that $i$ company's stock price at time $t$ is determined by the market's prediction of the present value of company $i$ 's expected future earnings. If we assume the company's earnings and sales ratio will maintain stable with only temporary variation over different periods, that is:
$\frac{X_{i t}}{S_{i t}}=\lambda_{i}+\mu_{i t}, E\left(\mu_{i t}\right)=0, \operatorname{Cov}\left(\mu_{i t}, S_{i t}\right)=0$

Where $S_{i t}$ is $i$ company's sales at time $t$.

If we substitute this expression into equation (1), then the equation (1) can be rewrite as:

$$
\begin{aligned}
& P_{i t}=\sum_{l=1}^{\infty} \beta_{i}^{l} E_{t}\left(\lambda_{i} S_{i t+l}+\mu_{i t} S_{i t+l}\right) \\
& =\lambda i \sum_{l=1}^{\infty} \beta_{i}^{l} E_{t}\left(S_{i t+l}\right)
\end{aligned}
$$

If the current and past sales are related to the future sales, then the current sales will have incremental information content for the market. We can express the influence of past sales on the t period stock price as:

$P_{t}=\alpha_{1}+a_{1} S_{1}+a_{2} S_{t-1}+\ldots+e_{t} \quad$,

$E\left(e_{t}\right)=0$

Where, $e_{t}$ represents current price reaction to the non-sales related information. On the other hand, the current stock prices should reflect all information related to the future sales (e.g., company's expansion project). The market will show the stock prices lead the sales. The relationship can be expressed as:

$S_{t+1}=\alpha_{2}+d_{1} S_{t+l-1}+d_{2} S_{t+l-2}+\ldots+c P_{t}+\varepsilon_{t+l}(4)$

Where $\varepsilon_{t+1}$ is the new information in period $t+l$ which will affect the salesequation (4). $P_{t}$ is the stock prices at period $t$, which includes information related to the future sales in period $t+l$.

From (3) and (4) together, we can see the information transfer between stock prices and sales could be bi-directional (i.e., there is dual dynamic relationship between the two variables). Therefore, we should use equations (3) and (4) simultaneously to take into account the possible interaction between prices and sales. In reduced form, it can be expressed as:

$S_{t}=C_{1}+A_{1} S_{t}+B_{1} P_{t}+D_{1} \varepsilon_{t}+F_{1} e_{t}(\mathbf{5})$

$P_{t}=C_{2}+A_{2} S_{t}+B_{2} P_{t}+D_{2} \varepsilon_{t}+F_{2} e_{t}$

where

$A_{i}=\left(A_{i 1} L+A_{i 2} L^{2}+\ldots+A_{i p} L^{p}\right) \quad i=1,2$

$B_{i}=\left(B_{i 1} L+B_{i 2} L^{2}+\ldots+B_{i p} L^{p}\right) \quad i=1,2$

$D_{1}=\left(1+D_{11} L+D_{12} L^{2}+\ldots+D_{1 q} L^{q}\right)$

$D_{2}=\left(D_{21} L+D_{22} L^{2}+\ldots+D_{2 q} L^{q}\right)$

$F_{1}=\left(F_{11} L+F_{12} L^{2}+\ldots+F_{1 q} L^{q}\right)$

$F_{2}=\left(1+F_{21} L+F_{22} L^{2}+\ldots+F_{2 q} L^{q}\right)$

$L$ is the lag operator. 
We propose the following hypothesis:

\section{Hypothesis: If sales has information}

content, sales will affect the share prices

in the dynamic model (i.e., $A_{2}\left(\right.$ or $\left.D_{2}\right)$ in

equation (5) will not be 0 ).

\section{Variable Identification and Sample Selection}

The sales variable in the study is the total sales for the whole industry. The proxy variable used for the stock prices is the sum of market value of all companies in the industry. We also deflated the industry sales and stock prices by using the first month data in the observation period as the base. That is, the industry sales index for industry $i$ at time $t$ should be:

$S_{i t}=\sum_{j=1}^{n_{i}} S_{j t}^{f} / \sum_{j=1}^{n_{i}} S_{j B}^{f}$

Where

$S_{i t} \quad$ : the industry sales index for industry $i$ at time $t$

$S_{j t}^{f} \quad$ : the sales of company $j$ in the

$n_{i} \quad$ : number of companies, industry $i$

$S_{j B}^{f} \quad$ : the first month sale of company $j$ in the industry

The stock price index for industry $i$ at period $t$ is:

$P_{i t}=\frac{\sum_{j=1}^{n_{j}} P_{j t}^{f} \times S T_{j t}^{f}}{\sum_{j=1}^{n_{j}} P_{j B}^{f} \times S T_{j B}^{f}}$

$P_{i t} \quad:$ stock price index for industry $i$ at period $t$

$P_{j t}^{f} \quad:$ stock price for company $j$ in the industry at period $t$

$S T_{j t}^{f} \quad$ : number of shares for company $j$ in the industry at period $t$

$P_{j B}^{f} \quad:$ the first month stock price for company $j$ in the industry

$S T_{j B}^{f} \quad$ : number of shares for company $j$ in the industry in the $1^{s t}$ month

We choose the first trading day after the $10^{\text {th }}$ of each month as the measurement date for the stock prices.

\section{Empirical Analysis}

This study uses data from three key industries in Taiwan - Electronics, Plastics, and Textiles, to observe the interrelationship between the industrial sales index and the industrial stock prices index. The data of industrial sales and industrial price index of the first trading day after the $10^{\text {th }}$ day of each month were fit to the proper VARMA model as follows,

$Z_{t}=C+\Phi_{1} Z_{t-1}+\cdots+\Phi_{p} Z_{t-p}+U_{t}+\theta_{1} U_{t-1}+\cdots+\theta_{q} U_{t-q}$

The sales index for the Textile industry has shown some seasonal pattern while there is little seasonal pattern of the stock price index for the same industry. The fitted VARMA model has shown "nonstationary" condition for the two variables' time series. We take first order difference of each variable to get $\Delta S_{t}\left(=S_{t}-S_{t-1}\right)$ and $\Delta P_{t}\left(=P_{t}-P_{t-1}\right)$ then fit the VARMA model with the converted first-order difference time series. The new VARMA model is:

$$
\begin{aligned}
\Delta S_{t}= & 0.004-0.593 \Delta S_{t-12}+\varepsilon_{t}-0.491 \varepsilon_{t-1} \\
& (0.003) \text { a } \quad(0.096) \\
\Delta P_{t}= & 0.017-0.495 \Delta \mathrm{S}_{t-12}+\eta_{t}+1.421 \varepsilon_{t-1} \\
& (0.023) \quad(0.381)
\end{aligned}
$$

a: standard deviation of the coefficient

From the above VARMA model, we can see the current month sales change is related to the sales change of same month last year and the change of last month unexpected sales. This illustrates a one-way relationship between sales and stock prices. That is, sales change will affect stock prices change but stock price changes will not impact the sales change.

For the Plastics industry, the bi-variate time series demonstrates a seasonal sales pattern and an irregular stock price pattern. Similar to the Textile industry, we need to use the first order difference transformation to deal with the nonstationary problem associated with the sales and stock prices time series. The estimated VARMA model for the Plastic industry is:

$$
\begin{aligned}
\Delta S_{t}= & 0.002+\varepsilon_{t}-0.287 \varepsilon_{t-1}+0.383_{t-12} \\
& (0.124) \quad(0.118) \\
\Delta P_{t}= & 0.041+\eta_{\mathrm{t}}-0.309 \eta_{t-12}+0.839 \varepsilon_{t-1}-0.327 \varepsilon_{t-12} \\
& (0.021)
\end{aligned}
$$


The VARMA model indicated that last month's unexpected sales and same month last year's unexpected sales changes will affect current period sales. Stock price index change is influenced by the unexpected price change for the same month last year, and last month's unexpected sales and same month last year's unexpected sales changes. In fact, the coefficient matrix shows that the $(1,12)$ step moving average of the coefficient matrix is a triangular matrix which implies sales change will affect stock price change but stock price change do not affect the sales change.

The resulting VARMA model for the Electronics industry is:

$Z_{t}=\varepsilon_{t}-0.757 \varepsilon_{t-1}$

$$
\begin{aligned}
\Delta P_{t}= & 0.363-0.369 \Delta \mathrm{P}_{t-11}+1.131 Z_{t-11}+\eta \\
& (0.118) \quad(0.172) \quad(0.536)
\end{aligned}
$$

This model indicates that the one-year difference transformation of the current period sales change is related to the one-year difference of last period's sales change and not related to the change in stock price. The current period stock price is influenced by the stock price changes 11 months ago and one-year difference of the sales change 11 months ago $\left(Z_{t-11}\right)$. Again, the evidence supports the one-way dynamic relationship between sales index and stock price index. That is, the one-year difference of the sales change will affect stock price change but no reciprocal relationship exists.

In summary, the empirical result of this study indicated that, each industry has a different fitted VARMA model with the use of first order difference transformation in most cases. The dynamic relationship demonstrated in these VARMA models show consistently a one-directional relationship from sales to stock price which support the proposed hypothesis. The result does not support the notion of stock price changes having information content related to the future sales.

\section{Conclusion}

We selected three leading industries in Taiwan - Electronics, Plastics, and Textiles, and using the industrial sales index and industrial stock price index to fit the proper VARMA model which in turn provides evidence of a one-direction relationship between sales and stock prices. The empirical result on the direction of information transfer between sales and stock prices is highly consistent across all industries. Sales can transmit relevant information to the market and affect the stock prices, but stock prices have not shown to release any relevant information about future sales.

\section{Reference}

[1] Miller, M.H. and F. Modigliani, 1961, Dividend Policy, Growth and the Valuation of Shares, Journal of Business 34, 411-433.

[2] Ball, R. and P. Brown, 1968, An Empirical Evaluation of Accounting Income Numbers, Journal of Accounting Research 6, 159-178.

[3] Beaver, W.R., R. Clarke, and W. Wright, 1979, The Association Between Unsystematic Security Percentage Change in Prices and the Magnitude of Earnings Forecast Errors, Journal of Accounting Research 17, 316-340.

[4] Beaver, W.R., R. Lambert, and D. Morse, 1980, The information content of security prices, Journal of Accounting and Economics 2, 3-28.

[5] Beaver, W.H. (1968) The information content of annual earnings announcements. Journal of Accounting Research 6, 67-92.

[6] Patell, J. M. and M.A. Wolfson, 1981, The ex ante and ex post price effects of quarterly earnings announcements reflected in option and stock prices. Journal of Accounting Research 19, 434-458.

[7] Beaver, W.R., R. Lambert, and S. Ryan, 1987, The information content of prices: A second look, Journal of Accounting and Economics 9 , 139-158.

[8] Beaver, W. H., M. McAnally and C.H. Stinson, 1997, The Information Content of Earnings and Prices: A Simultaneous Equations Approach, Journal of Accounting and Economics 23, 53-81.

[9] Allen, D.E., S. Cruickshank and N. Morkel-Kingsbury, "A Comment on 'The Information Content of Earnings and Prices: A Simultaneous Equations Approach' by W.H. Beaver, M.L. McAnally and C.H. Stinson (1997)", Working Paper, School of Finance and Business Economics, Edith Cowan University, and School of Business and Economics, Monash University.

[10] Lee, Charles M.C., James Myers, and Bhaskaran Swaminathan. 1999. "What Is the Intrinsic Value of the Dow?" Journal of Finance, vol. 54, no. 5 (October): 1693-1741. 